\title{
Osteocondrite (Osteocondrose) Dissecante (OCD) $)^{(*)}$ Osteochondritis (Osteochondrosis) Dissecans (OCD)
}

\author{
Flávia Aiko Sakamoto ${ }^{(1)}$, André Yui Aihara ${ }^{(1)}$, Artur da Rocha Corrêa Fernandes ${ }^{(1)}$ e Jamil Natour ${ }^{(2)}$
}

\section{INTRODUÇÃO}

Osteocondrite dissecante (OCD) é uma condição adquirida de etiologia desconhecida, caracterizada pela necrose focal do osso subcondral de articulações ${ }^{(1)}$. A importância do diagnóstico precoce desta entidade deve-se ao potencial de cura espontânea num momento inicial. Ocorre geralmente em adolescentes e adultos jovens do sexo masculino, sendo o joelho o local mais acometido, seguido pelo tálus. O termo mais adequado para esta alteração é osteocondrose dissecante, pois se sabe que não há processo inflamatório local. Existem duas teorias quanto à etiopatogenia, são elas: a teoria traumática/mecânica, relacionada com o aumento da atividade e microtraumas repetitivos, e a predisposição familiar/hereditária ${ }^{(2)}$. Entretanto, a correlação anátomopatológica e o curso in vivo da OCD ainda são baseados em observações cirúrgicas e histológicas, e em estudos experimentais ${ }^{(2)}$. Inicialmente há demarcação do osso subcondral com necrose, sem comprometimento macroscópico da cartilagem sobrejacente. Posteriormente, adjacente ao osso necrótico, forma-se uma zona de transição, que é preenchida por tecido de granulação, composta por tecido fibrocartilaginoso e capilares vasculares. Nesta etapa, a lesão pode ter cura espontânea, ou evoluir com separação do fragmento ósseo com ou sem alteração cartilaginosa. Por fim, há extrusão do fragmento, com formação de corpo livre intra articular e cratera na superfície óssea ${ }^{(2,3)}$. Há autores que separam a OCD em duas entidades, a OCD juvenil e a OCD do adulto, diferenciadas pelo início dos sintomas com relação ao fechamento da placa epifisária. O motivo dessa distinção deve-se ao melhor prognóstico das lesões na forma juvenil $^{(3)}$. Como também, a longo prazo, a OCD do adulto predispõe a alterações degenerativas secundárias, com antecipação dos sintomas em cerca de 10 anos quando comparado a indivíduos sãos ${ }^{(2)}$. Não devemos confundir a OCD com osteonecrose pós corticoterapia, hemoglobinopatias, doença de Gaucher, doença de Caisson's(2) ou com a “osteonecrose espontânea"(2,4).

\section{LOCALIZAÇÃO}

O local mais comumente envolvido é o côndilo femoral (Figura 1), seguido pelo tálus (Figura 2), o capítulo do úmero (Figura 3) e a superfície superior do quadril. No fêmur, a face lateral do côndilo medial é acometida em $85 \%$ dos casos e o côndilo lateral em $15 \%{ }^{(1)}$. No tálus, as superfícies mais envolvidas são a medial e lateral do dômus, e menos comumente a central ${ }^{(2,1)}$. Locais raramente comprometidos são a cabeça do I metatarso, cabeça umeral, escafóide $^{(2,1)}$ e a cavidade glenóide ${ }^{(5)}$. Pode ser bilateral em cerca de $5 \%$ dos casos (Figura 4$)^{(2)}$.

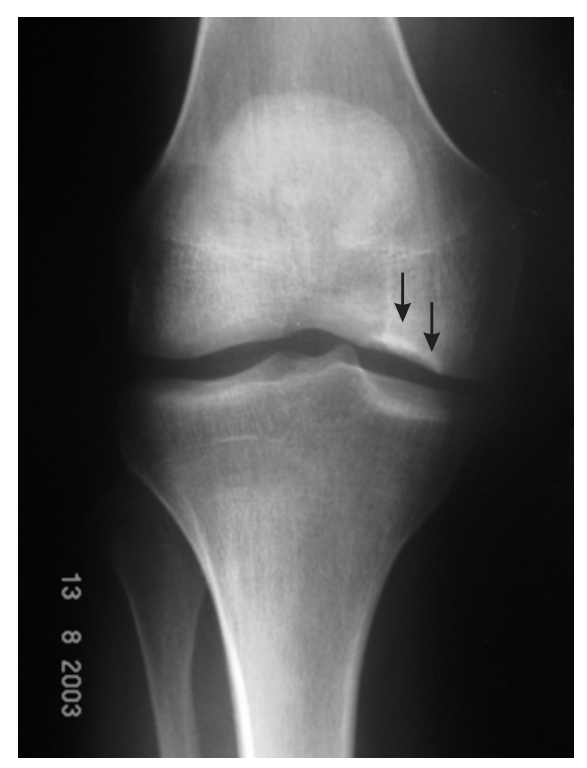

FIGURA 1- 0steocondrite dissecante no côndilo femoral medial.

\footnotetext{
* Departamento de diagnóstico por imagem da Universidade Federal de São Paulo (EPM/Unifesp).

1. Departamento de diagnóstico por imagem da EPM/Unifesp.

2. Disciplina de Reumatologia da (EPM/Unifesp).
}

Endereço para correspondência: Artur da Rocha Corrêa Fernandes. Departamento de diagnóstico por imagem da EPM/Unifesp. Rua Botucatu, 740, CEP 04023-900, São Paulo, SP. 


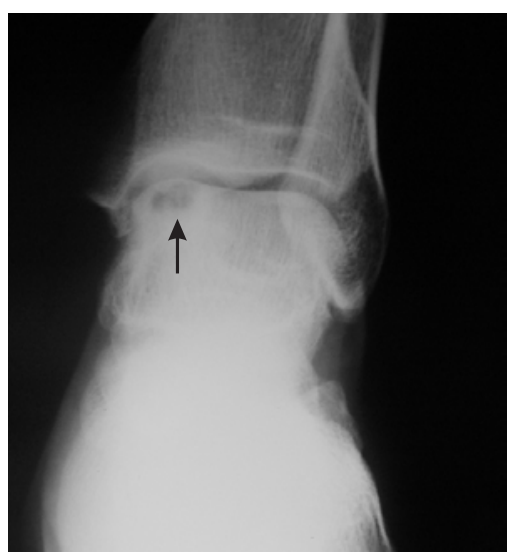

FIGURA 2- Osteocondrite dissecante na superfície medial do dômus talar.

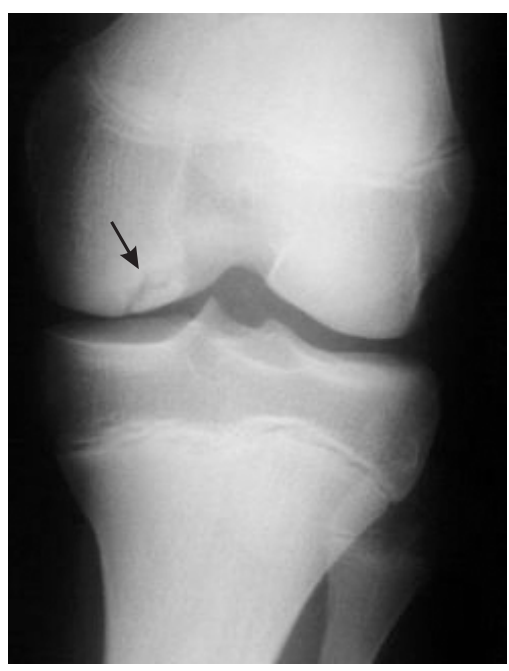

FigURA 3-0steocondrite dissecante com centro radiodenso no côndilo femoral medial.
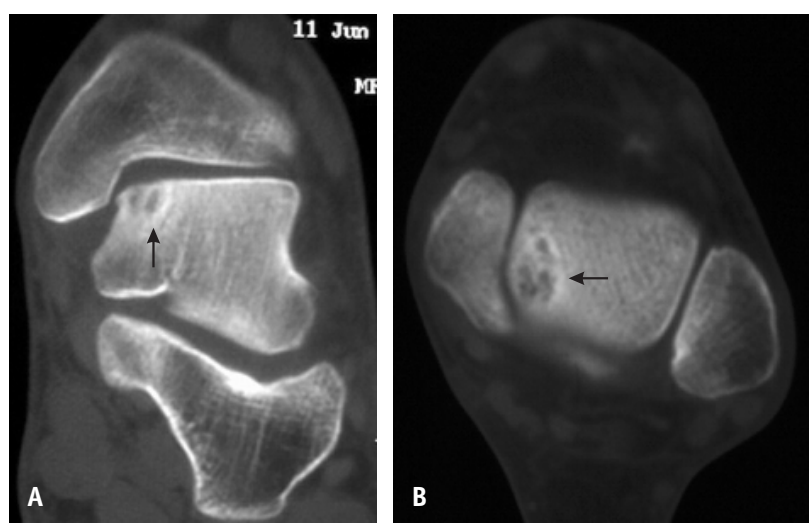

Figura 4- Tomografia computadorizada do tálus mostrando lesão heterogênea predominantemente radioluzente, ovalada, na porção medial do dômus. a) Corte no plano coronal. b) Corte no plano axial.

\section{AVALIAÇÃO CLÍNICA}

Geralmente acomete indivíduos masculinos entre a segunda e quarta décadas. O quadro clínico pode ser assintomático, ou determinar sintomas intermitentes como dor em movimento dependente ao saltar, agachar ou subir escadas; limitação do movimento e estalidos. Algumas vezes está associada a edema discreto, mas nunca a hematoma. Caso haja corpos livres, pode haver travamento do joelho. Em razão dos sintomas frustros, o diagnóstico é feito freqüentemente após vários anos do início do quadro ou de forma incidental em estudos radiológicos ${ }^{(2,6)}$.

\section{ARTROSCOPIA}

Gulh, em 1982, propôs uma classificação artroscópica das alterações morfológicas no joelho em quatro estágios. No primeiro estágio, a cartilagem está intacta, parcialmente amolecida e abaulada. No segundo, notam-se lesões/fissuras incipientes na cartilagem. No terceiro, há fragmento ósseo parcialmente destacado; e no quarto observam-se cratera e corpo livre. Novos e complexos esquemas foram criados, mas não têm relevância terapêutica ${ }^{(2)}$.

\section{DIAGNÓSTICO POR IMAGEM}

\section{RADIOGRAFIA CONVENCIONAL}

Os exames radiográficos geralmente estabelecem o diagnóstico de OCD corretamente. Entretanto, não fornecem dados que determinem uma conduta terapêutica apropriada, já que há freqüente discrepância entre os achados radiográficos e os cirúrgicos ${ }^{(2)}$. O achado radiográfico característico é o foco radioluzente arredondado ou ovalado do osso subcondral, de contornos irregulares, que pode apresentar área de esclerose central, relacionada com fragmento ósseo impactado (Figura 5). As incidências preconizadas para a avaliação de OCD no joelho são a antero-posterior, lateral e do túnel; e as necessárias para estudar o tálus são a antero-posterior, oblíqua em $30^{\circ}$ e a lateral ${ }^{(1,2,6)}$.

\section{TOMOGRAFIA COMPUTADORIZADA (TC)}

A TC fornece um bom delineamento anatômico da lesão osteocondral (Figuras 6a e 6b), entretanto não avalia o potencial de cura da lesão. Davies e Cassar-Pullicino, em 1989, utilizaram a artrotomografia no tornozelo e têm conseguido estabelecer o prognóstico de lesões da cartilagem talar ${ }^{(2)}$. 

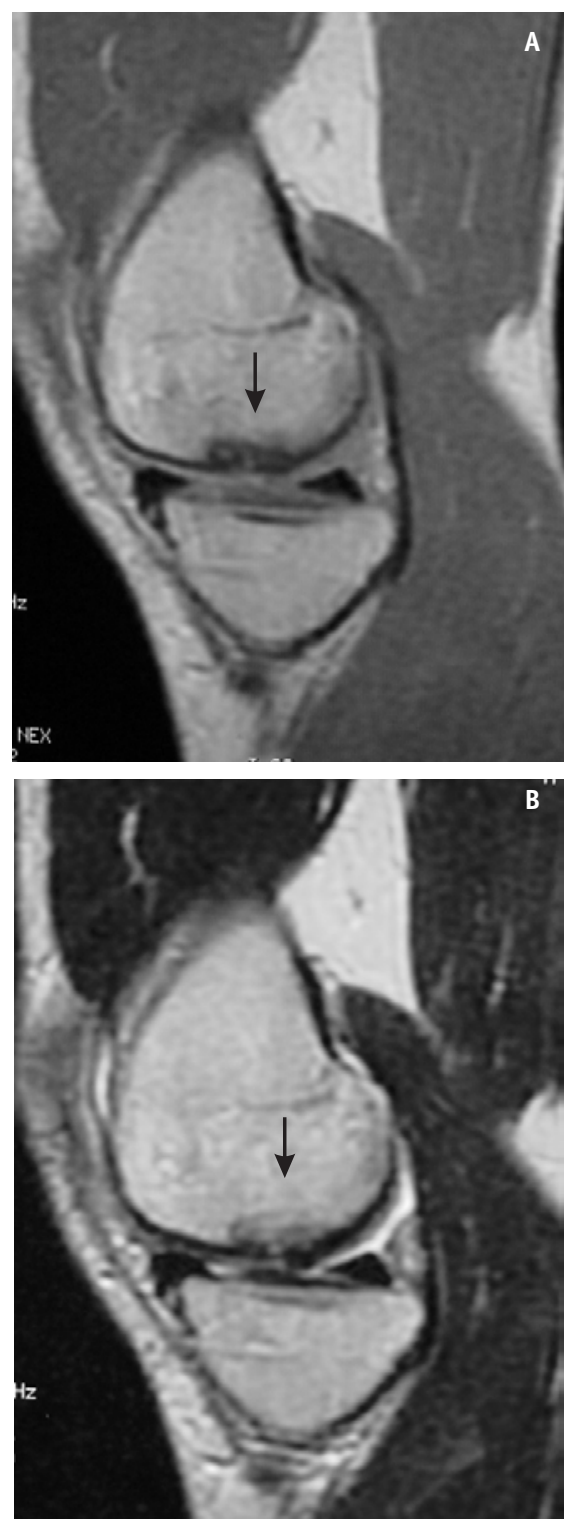

Figura 5- Ressonância magnética do joelho no plano sagital, mostrando lesão subcondral do côndilo femoral medial, apresentando hiposinal na seqüência ponderada em T1 (a) e T2 (b), com cartilagem sobrejacente preservada.

\section{CINTILOGRAFIA}

Aceitando a teoria isquêmica, Cahill e Berg, em 1983, propuseram a descrição e o estagiamento da OCD. Eles concluíram que a chance de cura correlacionava-se com a extensão da atividade local(2).

\section{RESSONÂNCIA MAGNÉTICA (RM)}

A RM demonstra as alterações ósseas e cartilagíneas mais precocemente que a radiografia convencional ${ }^{(1,6)}$, e tem
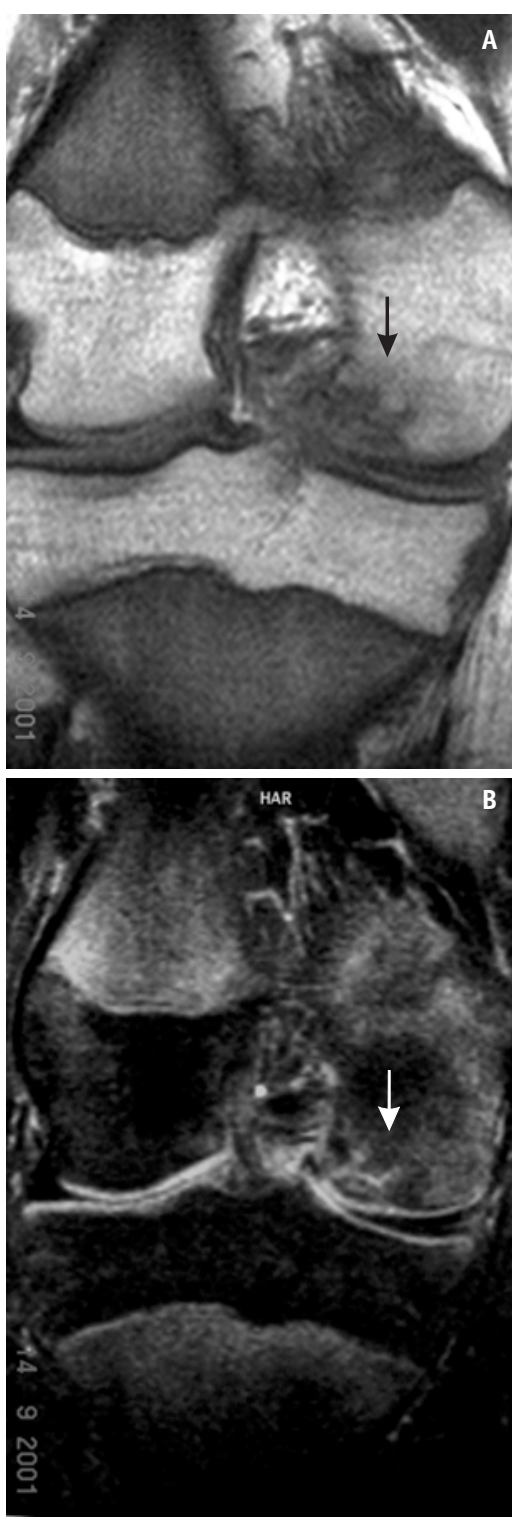

FiguRA 6- Ressonância magnética do joelho no plano coronal, mostrando lesão subcondral do côndilo femoral medial, apresentando hiposinal na sequiência ponderada em T1 (a) e T2 (b), com cartilagem sobrejacente preservada, e halo com hipersinal em $\mathrm{T} 2$.

acurácia semelhante ao exame artrográfico ${ }^{(7,8)}$. Fornece dados sobre a extensão, morfologia e perfusão da lesão, além de ser um método não invasivo que avalia a condição local com alta sensibilidade ${ }^{(4)}$. O aspecto clássico da OCD à RM corresponde à alteração focal do osso subcondral, com forma semi-oval ou semicircular, relativamente demarcada, com hipossinal em T1 e hipossinal heterogêneo em T2 (Figura 7). Numa fase inicial, em que há processo reparativo ativo, e a lesão está quase ou completamente vascularizada, 
observa-se realce difuso após a injeção endovenosa do meio de contraste paramagnético. A zona de transição, preenchida com tecido de granulação, tem hipossinal em T1, hipersinal em T2 e realce com contraste. Após a separação do fragmento, forma-se um espaço preenchido por líquido que, dependendo da separação ser completa ou parcial, haverá líquido em todo a periferia do fragmento ou não. À RM, este fluido apresenta hipossinal em T1, hipersinal em T2 e não tem realce após o contraste (Figura 8). Os sinais que indicam instabilidade do fragmento são hipersinal ao redor do fragmento em T2; áreas císticas focais com mais de $5 \mathrm{~mm}$, localizadas profundamente à lesão da OCD; deformidade ou fissuras da cartilagem sobrejacente; e fluido circundando o fragmento $^{(2,7,9)}$. A RM também avalia as dimensões do leito ósseo e o corpo livre. O hipersinal ao redor do fragmento em T2 é o sinal de instabilidade mais freqüentemente observado; os demais, apesar de menos comuns, são $100 \%$ específicos $^{(7)}$. Outro parâmetro prognóstico é a dimensão da área da lesão. Quanto menor a área da superfície acometida, melhor será a evolução ${ }^{(9)}$. Esses sinais de RM foram determinados para a OCD do joelho, mas podem ser aplicados para o tornozelo. É importante diferenciar a OCD da fratura aguda. Esta última apresenta extenso edema medular ósseo circunjacente ${ }^{(2)}$. Outra condição a ser lembrada é que, na avaliação pós-cirúrgica de fixação do fragmento ósseo, pode haver o hipersinal em T2 por longo período, atribuído ao processo de reparação ${ }^{(2,10)}$. Com o intuito de melhorar a avaliação da cartilagem articular, podese introduzir solução de contraste paramagnético na cavidade articular e realizar estudo com $\mathrm{RM}^{(2,6)}$.
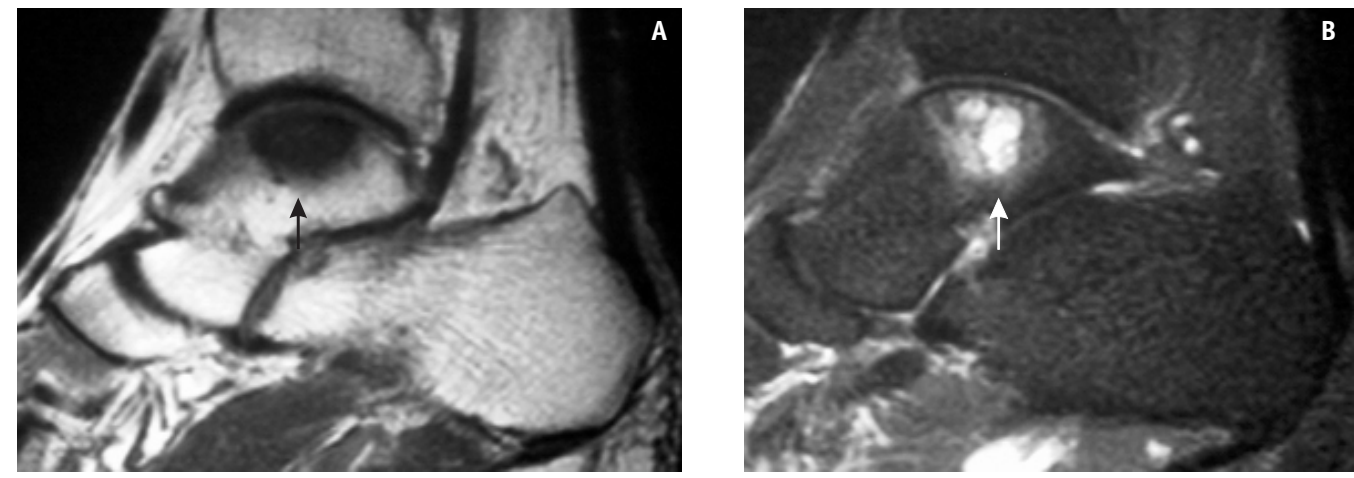

FiguRA 7- Ressonância magnética do tálus no plano sagital, mostrando lesão subcondral do dômus, apresentando cistos caracterizados por hiposinal na seqüência ponderada em T1 (a) e hipersinal em T2 (b), com discreto edema medular adjacente.
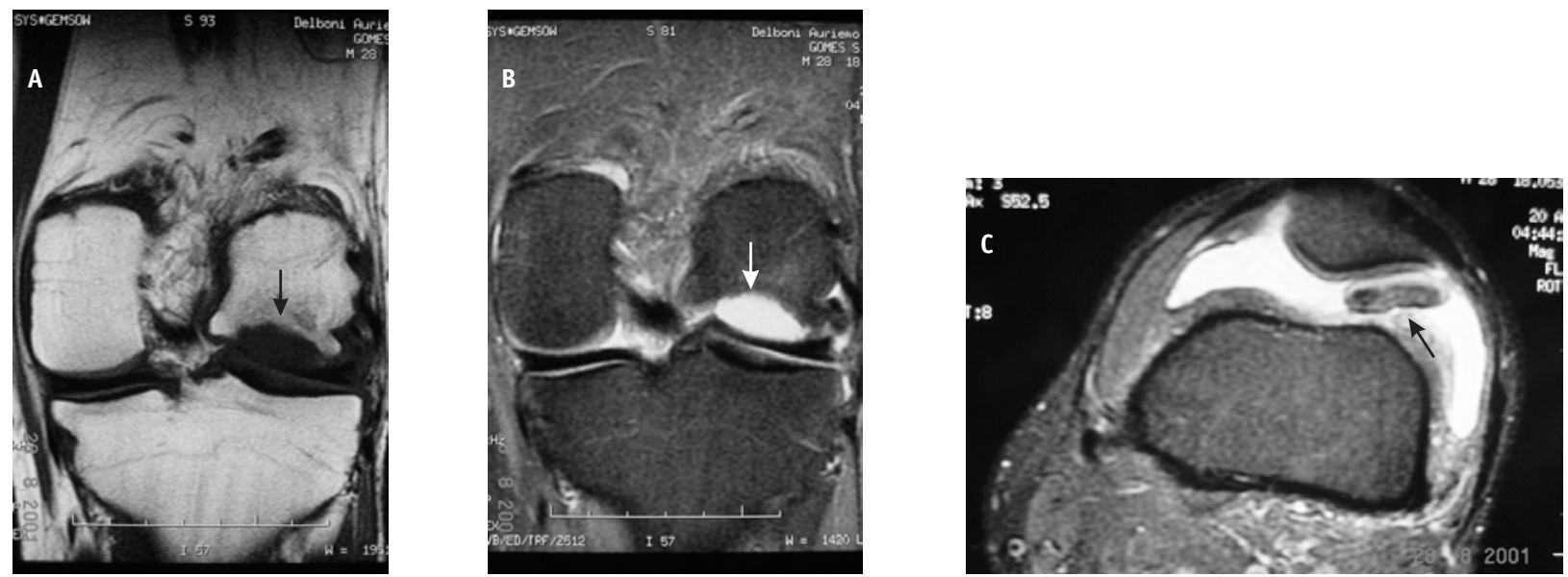

FIGURA 8- Ressonância magnética do joelho esquerdo no plano coronal, mostrando cratera no côndilo femoral lateral, preenchido por fluido caracterizado por hiposinal na seqüência ponderada em T1 (a) e hipersinal em T2 (b). Observa-se o fragmento destacado na cavidade articular, corpo livre no compartimento patelo-femoral, na imagem axial, ponderada em T2 (c). 


\section{TRATAMENTO}

Pode ser conservador ou cirúrgico, dependendo da estabilidade do fragmento. Numa lesão com aspecto estável determinado pela RM e/ou pelo estudo artrográfico, preconiza-se terapêutica conservadora, com retirada de carga do membro afetado por 6 a 12 meses. Caso persista dor e os achados de RM demonstrem redução do processo de reparação, é indicado o tratamento cirúrgico. $\mathrm{Na}$ OCD instável, também é recomendada a intervenção cirúrgica. Há melhor prognóstico dos pacientes jovens com placa epifisária aberta, e lesões que apresentam a cartilagem sobrejacente intacta. Nessas duas condições há maior incidência de evolução para cura espontânea ${ }^{(3,6,8)}$.

Concluindo, a osteocondrite (osteocondrose) dissecante é uma lesão primariamente óssea com envolvimento da

\section{REFERÊNCIAS}

1. Rowe LJ, Yochum TR: Hematologic and vascular disorders. In: Essentials of Skeletal Radiology. Yochum TR, Rowe LJ: 2.a ed, Baltimore, Williams \& Wilkins, 1295-301, 1996.

2. Bohndorf K: Osteochondritis (osteochondrosis) dissecans: A review and new MRI classification. Eur Radiol 8: 103-12, 1998.

3. Hughes JA, Cook JV, Churchill MA, et al: Juvenil osteochondritis dissecans: a 5-year review of the natural history using clinical and MRI evaluation. Pediatr Radiol 33: 410-17, 2003.

4. Stoller DW, Cannon Jr WD, Anderson LJ: O joelho. In: Ressonãncia Magnética em Ortopedia \& Medicina Desportiva. Stoller DW, 2.a ed, Philadelphia, Lippincott-Raven, 393-6, 2000.

5. Yu JS, Greenway G, Resnick D: Osteocondral defect of the glenoide fossa: cross-sectional imaging features. Radiology 206: 35-40, 1998. cartilagem articular secundariamente. Há formação de uma zona transicional após necrose óssea que tem potencial de cura, mas pode evoluir para deformidade óssea. Etiologicamente, a teoria mecânica/traumática é a mais aceita. A predisposição familiar/hereditária pode ser considerada um fator em alguns pacientes, particularmente em crianças e adolescentes. É grande a diferença no curso clínico e no prognóstico de pacientes com fise aberta e fechada. A OCD é geralmente diagnosticada pela radiografia simples, que não fornece dados quanto à instabilidade da lesão. A RM é o exame de escolha para o diagnóstico. A RM associada ao quadro clínico determina a conduta terapêutica da OCD. A RM também auxilia na indicação da realização de artroscopia e/ou artrotomia, bem como no seguimento da cicatrização $^{(1)}$.

6. Resnick D, Goergen TG: Phisical injury: concepts and terminology. In: Diagnosis of bone and joint disorders. Resnick D. 4.a ed, Philadelphia, W B Saunders Company, 2689-708, 2002.

7. De Smet AA, Ilahi AO, Graf BK: Reassessment of the MR criteria for stability of osteochondritis dissecans in the knee and ankle. Skeletal Radiol 25: 159-63, 1996.

8. Jürgensen I, Bachmann G, Schleicher I, et al: Arthroscopic versus conservative treatment of osteocodritis dissecans of the knee: value of magnetic resonance imaging in therapy planning and follow-up. Arthroscopy 18: 378-86, 2002.

9. De Smet AA, Ilahi AO, GrafBK: Untreated osteochondritis dissecans of the femoral condyles: prediction of patient outcome using radiographic and MR findings. Skeletal Radiol 26: 463-7, 1997.

10. Boutin RD, Januario JA, Newberg A, et al: MR imaging features of osteochondritis dissecans of the femoral sulcus. AJR 180: 641-5, 2003. 